\title{
COMPARATIVE STUDY FOR DETECTION OF H. PYLORI INFECTION BY RAPID UREASE TEST AND HISTOPATHOLOGICAL EXAMINATION IN AL-AMEEN MEDICAL COLLEGE
}

\author{
Sushila Garag1, Basavaraj Nagur²
}

${ }_{1}^{1}$ Associate Professor, Department of General Surgery, Al Ameen Medical College, Vijayapura, Karnataka, India.

${ }^{2}$ Assistant Professor, Department of General Surgery, Al Ameen Medical College, Vijayapura, Karnataka, India.

\section{BACKGROUND}

ABSTRACT

H. pylori infection is seen in more than 50 percent of world population and is more common in developing countries than in western countries. We wanted to study the incidence of $\mathrm{H}$. pylori infection in Al-Ameen Medical College and also compare the sensitivity and specificity of rapid urease test with that of histopathological examination for the detection of H. pylori in specimens of gastric biopsy.

\section{METHODS}

This study was conducted in General Surgery Department, Al-Ameen Medical College, Vijayapura, from 1 June 2018 to 30 September 2018. It is a prospective, comparative study, done in 100 patients, for the detection of H. pylori infection by rapid urease test and histopathological examination.

\section{RESULTS}

A total of 100 patients was recruited for the study. The median age of the study participants was 45 years. 77 patients were Rapid Urease Test (RUT) positive \& 80 patients were positive in histopathological examination (HPE). Sensitivity and Specificity of RUT and HPE were $91.25 \%$ and $80 \%$ respectively.

\section{CONCLUSIONS}

RUT is relatively inexpensive and simple test and can be done routinely at all endoscopy centers, especially in developing countries.

HOW TO CITE THIS ARTICLE: Garag S, Nagur B. Comparative study for detection of H. pylori infection by rapid urease test and histopathological examination in Al-Ameen medical college. J. Evolution Med. Dent. Sci. 2019;8(17):1385-1387, DOI: $10.14260 /$ jemds $/ 2019 / 308$

\section{BACKGROUND}

H. Pylori infection is seen in more than 50 percent of world population and is more common in developing countries than in western countries. Helicobacter pylori (H. pylori) is the main causative pathogen in the pathogenesis of gastroduodenal ulcer, atrophic gastritis, gastric cancer, idiopathic thrombocytopenic purpura (ITP), iron deficiency anaemia, MALT lymphoma and vitamin B12 deficiency.(1) The cause being, low socioeconomic status, illiteracy and inadequate sanitation due to overcrowding for prevalence of H. pylori infection. Possible routes of transmission identified include oro-oral, faecal-oral and gastro-oral routes.[2] The various diagnostic tests done for detecting $\mathrm{H}$. pylori infection are rapid urease test, serology (IgG ELISA), histopathology, ${ }^{13} \mathrm{C}$-urea breath test (UBT) and polymerase chain reaction (PCR).[3,4,5] Among these tests, rapid urease test is highly specific for $\mathrm{H}$. pylori infection and is commonly used for the detection of $\mathrm{H}$. pylori infection at endoscopy.

'Financial or Other Competing Interest': None.

Submission 01-02-2019, Peer Review 15-04-2019,

Acceptance 22-04-2019, Published 29-04-2019.

Corresponding Author:

Dr. Basavaraj Nagur,

Dr. Nagur Hospital,

Dr. Nagur Education Campus,

College Road, Vijayapura,

Karnataka, India.

E-mail: sachin.nagur@gmail.com

DOI: $10.14260 /$ jemds $/ 2019 / 308$

\begin{abstract}
Aims and Objective
1. To study the incidence of $\mathrm{H}$. pylori infection in AlAmeen Medical College.

2. To compare the sensitivity and specificity of rapid urease test with that of histopathological examination for the detection of $\mathrm{H}$. pylori on gastric biopsy.
\end{abstract}

\section{METHODS}

\section{Study Design}

Comparative exploratory study.

\section{Study Setting}

This study was conducted in General Surgery Department, AlAmeen Medical College, Vijayapura, from 1 June 2018 to 30 September 2018. It is a prospective, comparative study done in 100 patients.

\section{Inclusion Criteria}

- Age- 18-75 years.

- All patients with dyspeptic symptoms attending.

\section{Exclusion Criteria}

- Patients who are already taking steroids, proton pump inhibitors( $\mathrm{PPI}$ ), $\mathrm{H}_{2}$ blockers and, warfarin, one week prior to endoscopy

- Severe medical illness,

- Active gastrointestinal bleeding,

- Already treated for H. pylori eradication.

- Patients who have undergone of gastric surgery.

- Patient who have taken Antibiotics 4 weeks prior to endoscopy. 
Detail information regarding chief complaint, use of NSAIDS and PPI were taken they were advised to stop the NSAIDS and PPIs drugs one week prior to endoscopy. HIV, HBsAg \& HCV status was done. An informed consent from all patients taken. Ethics committee was approval was taken.

\section{Procedure}

All patients were kept NBM for 6 hrs prior to endoscopy. 10\% Lignocaine spray was sprayed on the both tonsillar pillars, posterior pharyngeal wall and after waiting for 5 minutes, patient was taken in left lateral position with the head on a small pillow flexed forward and mouth tilting downward and a pulse oximeter was attached to the patient and endoscope was introduced after placing a mouth gag.

The scope was passed through the oropharynx and nudged through cricopharynx under vision with the voluntary swallowing movement of the patient. The scope was rapidly passed through the oesophagus doing a rough scanning and leaving the detailed mucosal examination to be done during withdrawal. 2 biopsy samples were taken from the Antrum and Pylorus each for RUT and HPE Examination. After confirming haemostasis, the scope was removed after deflating the stomach. 2 biopsies were placed on yellow paper of RUT kit after removing the plastic cover and a single drop of distilled water was placed on yellow paper and then plastic cover was again sealed with its own adhesive and results were observed after 1- 2 hrs. Change of colour of yellow paper to pink indicates an H. pylori infection, rest 2 sample for the Histopathological Examination. The patient was advised to start oral diet after 1 hour of procedure.

\section{Statistical Methods}

Data was analysed by descriptive analysis. Quantitative variables were expressed as means \pm standard deviation while Qualitative variables were expressed as percentages. The test performance was assessed by determining sensitivity, specificity, positive predictive value, negative predictive value and diagnostic accuracy. Data was analysed using SPSS software v.23.0 and Microsoft office 2007.

\section{RESULTS}

A out of 100 patients $56(56 \%)$ were males and 44 (44\%) were females. The median age being 45 years. 76 patients out of 100 are RUT Positive Total 80 patients shows presence of H. pylori positive in HPE (shown in the Table No 1).

\begin{tabular}{|c|c|c|}
\hline Number of Patients (100) & Positive & Negative \\
\hline RUT & 77 & 23 \\
\hline HPE & 80 & 20 \\
\hline \multicolumn{3}{|c|}{ Table 1 } \\
\hline
\end{tabular}

Sensitivity and Specificity of RUT and HPE were 91.25\% and $80 \%$ respectively Positive \& Negative Predictive Values were $94.81 \%$ \& $69.57 \%$ respectively (Shown in the Table 2)

\begin{tabular}{|c|c|}
\hline Sensitivity & $91.25 \%$ \\
\hline Specificity & $80.00 \%$ \\
\hline Positive Predictive Value & $94.81 \%$ \\
\hline Negative Predictive Value & $69.57 \%$ \\
\hline Accuracy & $89.00 \%$ \\
\hline \multicolumn{2}{|c|}{ Table 2} \\
\hline
\end{tabular}

\section{DISCUSSION}

The upper GI endoscopy is routinely done in patients with upper GI bleed in epigastric pain, dyspepsia, epigastric pain and chest pain.[6] The rapid urease test being less expensive and having instant results compare to HPE, is widely use to detect during routine upper GI Endoscopy frequently used test for the diagnosis of $\mathrm{H}$. pylori infection in routine gastrointestinal endoscopy practice. Moreover RUT has been proved to be high sensitivity and more specificity and has clinical accuracy. Because of its rapid result to prove H. pylori infection before the patient leaves the endoscopic unit it is considered as extremely valuable. In case of negative RUT and suspected Malignancy Histological diagnosis of H. pylori infection is usually reserved.

In our study 77 patients were detected positive by RUT method. This is comparable with study conducted by the Korle Bu Teaching Hospital, Accra, Ghana, [6,7] found RUT is accurate for the diagnosis of $\mathrm{H}$. pylori infection. Its use will serve as a good alternative to histology in management of patients with dyspepsia in resource poor environments, except in patients who need histology for reasons other than H. Pylori diagnosis. In our study 80 patients were detected positive by HPE method. This is comparable with other study.[8] RUT and HPE all are high sensitive and specific to diagnose H. pylori infection.[9] The sensitivity was $96.38 \%$ and specificity was $74.47 \%$. This is comparable with other study.[10]

\section{CONCLUSIONS}

Diagnosis of $\mathrm{H}$. pylori infection by endoscopy, needs an experienced endoscopist. It has low sensitive and specificity. RUT is simple, is less expensive and gives rapid results. RUT should be routinely done in all endoscopy centers. RUT is more accurate for the diagnosis of $\mathrm{H}$. pylori infection compared to HPE examination.

\section{ACKNOWLEDGMENT}

The authors would like to thank Dr Sajid Mudhol, Professor and Head of Department, Deaprtment of Surgery for his support.

\section{REFERENCES}

[1] Shiotani A, Cen P, Graham DY. Eradication of gastric cancer is now both possible and practical. Semin Cancer Biol 2013;23(6 Pt B):492-501.

[2] Leclerc H. Epidemiological aspects of helicobacter pylori infection. Bull Acad Natl Med 2006;190(45):949-62.

[3] Goossens H, Glupczynski Y, Burette A, et al. Evaluation of commercially available second-generation immunoglobulin G enzyme immunoassay for detection of helicobacter pylori infection. J Clin Microbiol 1992;30(1):176-80.

[4] Klein PD, Malaty HM, Martin RF, et al. Noninvasive detection of helicobacter pylori infection in clinical practice: the 13C urea breath test. Am J Gastroenterol 1996;91(4):690-4.

[5] Brooks HJ, Ahmed D, McConnell MA, et al. Diagnosis of helicobacter pylori infection by polymerase chain reaction: is it worth it? Diagn Microbiol Infect Dis 2004;50(1):1-5. 
[6] Aduful H, Naaeder S, Darko R, et al. Upper gastrointestinal endoscopy at the Korle $\mathrm{Bu}$ Teaching Hospital, Accra, Ghana. Ghana Med J 2007;41(1):12-6.

[7] Baako BN, Darko R. Incidence of helicobacter pylori infection in Ghanaian patients with dyspeptic symptoms referred for upper gastrointestinal endoscopy. West Afr J Med 1996;15(4):223-7.

[8] Islam MDU, Rahman SHZ, Shamsuzzaman SM, et al. A comparative study among different invasive methods for the diagnosis of helicobacter Pylori. Faridpur Medical College J 2010;5(1):21-4.
[9] Redeen S, Petersson F. Tornkrantz E, et al. Reliability of diagnostic tests for helicobacter pylori infection. Gastroenterology Research and Practice 2011;2011:16.

[10] Jemilohun AC, Otegbayo JA, Ola SO, et al. Diagnostic accuracy of rapid urease test for the diagnosis of Helicobacter pylori gastic biopsies in Nigerian with dyspepsia. African Journal Clinical Experimental Microbiology 2011;12(2):62-6. 